\title{
A New Multi Objective Approach for Optimizing p-median Modeling in School Allocation using Genetic Algorithm
}

\author{
Clahildek Matos Xavier ${ }^{1}$, Marly Guimarães Fernandes Costa ${ }^{2}$ and Cícero Ferreira \\ Fernandes Costa Filho ${ }^{2}$
}

\author{
${ }^{1}$ Operations and Management Center of the Amazonian Protection System \\ (CENSIPAM) - Manaus, AM - Brazil \\ ${ }^{2}$ Federal University of Amazonas (UFAM) - Manaus, AM - Brazil \\ \{clahildek, marlygfcosta, cffcfilho\}@gmail.com
}

\begin{abstract}
This paper proposes a new methodology for a multi parameter approach using the p-median. The optimized solution must fulfill the following criteria: It must minimize distances between cities without a university to a city that has a university; It must prioritize cities with a higher population; It must prioritize cities with a lower United Nation Human Development Index. The use of a multiparametric approach was only possible by introducing the concept of a generalized distance. The results compare the existing distribution of campuses of the Federal system with the best location resulting from the multi parameter method proposed here. Locations for expansion of the current established university in Amazonas State, Brazil, are proposed.
\end{abstract}

\section{Introduction}

The percentage of the population in Brazil with access to college education is only $14 \%$, according to an OECD report (OECD, 2015), so there is much room for growth of higher education in Brazil. There are national policies in place intended to increase the population of college graduates, by means of grants that allow student admission to private Higher Education Institutions (HEI) through programs such as REUNI Restructuring and Expansion of Federal Universities (Ministry of Education, 2010). The REUNI program provide slots for $30 \%$ of the population within the age group of 18 to 24 , based on expanding current degree programs or creating new ones.

Provisions for expanding Higher Education Establishments (HEE) under REUNI towards the interior of Brazil are meant to establish, between years 2013 and 2018, an HEE in every city with either over 200,000 inhabitants or over $200 \mathrm{~km}$ away from state HEE campuses. Both criteria determined for the country, in a broad sense, require further analysis as far as the Brazilian Amazon region is concerned due to its distinctive features, including long distances between cities and low population density overall.

In order to provide an overview of this context, the state of Amazonas-Brazil comprises 62 cities and accounts for more than 180,000 Secondary School Pupils (SSP) living in the interior, totaling some $50 \%$ of the entire SSP population in the state (Brazilian Institute of Geography and Statistics, 2012). The other 50\% lives in the capital, Manaus. The SSP population is the one that will enter in an HEE. Access to such cities is typically managed by inland waterway navigation and the distances between locations can reach $1,500 \mathrm{~km}$ (National Waterway Transportation Agency, 
2013). Only the State capital city, Manaus, is home to a population greater than 200,000 dwellers (Brazilian Institute of Geography and Statistics, 2010).

Transportation of students from the interior to the nearest higher education establishment is time consuming and usually done by river. An alternative way to diminish such transportation difficulties, as per REUNI proposals, is to establish new higher education units in the interior. In Amazonas State, the federal system of higher education comprises 6 units. The aims of this paper concerns the higher education federal system of Amazonas State and are as follows: show that a high yet impractical number of higher education units are necessary to satisfy the REUNI criteria; evaluate the present distribution of higher education units of federal system; and propose a new methodology for selecting the best sites for constructing new college campuses.

The optimal location of schools has been addressed in the literature. Some studies solve a single objective optimization problem as follows. Pizzolato et al. (2004) proposed the use of uncapacitated p-median models (PMP) as well as capacitated (CPMP) to determine the location for $p$ schools in Vitoria, Espirito Santo state, Brazil. The optimization criterion is to minimize students total travel distance to the nearest school. A Lagrangian heuristic was used for the optimization problem. Currently, the total distance that students travel to schools they are assigned to was $99,220 \mathrm{~m}$. After determining location, by means of the uncapacitated p-median method, this distance decreased to $70,252 \mathrm{~m}$ and to $85,080 \mathrm{~m}$ with capacitated modeling.

In Teixeira et al. (2007), a variant of the p-median model was employed in order to determine $\mathrm{p}$ schools, in the city of Coimbra, Portugal. The optimization criterion is maximizing the accessibility of students to schools, with constraints on maximum and minimum capacity occupation. The optimization problem considered 11 existing secondary schools, 43 population centers and the total student-to-school distance of $21,097.8 \mathrm{~km}$. An XPRESS-MP mixed-integer programming optimizer was used. They achieved an optimized value of $10,861.2 \mathrm{~km}$ for the sum of distances, for 14 schools: 10 existing schools are maintained, 4 new schools are created and only one existing school is closed.

Menezes and Pizzolato (2014) proposed location of new schools, during the years 2015 - 2020, in the Guaratiba area, assessment region 5, Rio de Janeiro, Brazil, relying on capacitated p-median and maximum coverage models. They sought to minimize total student travel distance to the nearest school. Each school had a 1,300student maximum capacity and the total number of new schools was 15 . For the second model they sought to maximize population coverage within a pre-set $1,500 \mathrm{~m}$ maximum distance. Both approaches were solved using an AIMMS (Advanced Interactive Multidimensional Modeling System) tool based on a CPLEX solver.

Some studies solve multi objective problems. In Gac et al. (2009) the authors aim at maximizing individuals' utility and school profits. The objective function to be maximized defines the social benefits, which are modeled as aggregated quantities and measure the economic profits gained by schools and aggregate individuals' surplus. The authors employed a linear deterministic model. Amaya et al. (2015) proposed a model for determining the location of schools aiming at minimizing school fixed and overhead costs such as per-hour rates. Such work took into consideration the cost for opening and closing existing school facilities. The problem was optimized using CPLEX 9.1. They managed to reduce over $30 \%$ of total costs for a 5 -year period. 
The aforementioned papers that use the p-median model to determine school location have only a single objective: minimize student travel distance, with the center population as weight. This paper aims to evaluate application of a p-median model, using a new multi objective approach. The multi objectives considered are the following: minimize student travel distance, maximize population on centers with allocated schools and minimize the United Nation's Human Development Index (UN HDI) of centers with allocated schools. This new multi objective proposal for $\mathrm{p}$-median is only possible through the use of a generalized distance that encompasses three parameters: student travel distance, center population and UN HDI. In this paper, these parameters are normalized using median approach. Kariv and Hakimi (1979) have shown that the p-median problem is NP-hard. With the aim of obtaining the best location with the 62 cities, we employed the Genetic Algorithm - GA.

This paper is organized as follows. Section 2 presents how the Data used in the study were obtained. Section 3 shows the generalized distance, the normalization parameters and the evaluation index used to compare two location solutions. Section 4 presents the location problem modeling with the p-median model. Section 5 shows how GA was modeled to solve the p-median problem. Section 6 shows the results of locating a university or college for the entire set of cities using GA. Section 7 presents the conclusions and outlines the main contributions of this study.

\section{Data}

The Data used in this work consist of distances between cities, their populations and UN HDI. Population and UN HDI were acquired from the National Geography and Statistics Institute - IBGE $(2010,2012)$. The distances considered between cities were those corresponding to fluvial distances, which refer to the main means of transportation used in that region.

Some fluvial distances were established through data from the National Waterway Transportation Agency - ANTAQ (2013). Other distances missing from this database were acquired by means of one of the following methods: 1) subtraction between known routes along the same river; 2) using Google Maps API to measure the route between two cities set in different rivers or tributaries.

The Federal University of Amazonas (UFAM) has campuses in six cities: Manaus (capital), Parintins, Itacoatiara, Benjamin Constant, Coari, and Humaitá (Federal University of Amazonas, 2006).

\section{Generalized Distance, Normalization of Parameters and Evaluation Index}

Choosing a particular city for locating a college or university must abide by the following criteria: 1) cities with a larger SSP population must be prioritized; 2) cities with the lowest UN HDI must be prioritized; 3) minimizing the distances between those cities with established campuses and those without must be pursued. In order to insert such criteria into the solution by means of p-median, the concept of generalized distance was created to combine all these criteria into a single equation (Xavier et al., 2016). One generalized distance has been proposed, the generalized Manhattan distance, Eq.(1). This distance was named generalized for they include non-geometric coordinates. 


$$
d_{i j}^{\text {Man_gen }}=d_{i j}+\frac{\left|p_{i}-p_{j}\right|}{\left(\frac{p_{i}+p_{j}}{2}\right)\left|p_{i}-p_{j}\right|+k_{1}}+\frac{\left(\frac{H D I_{i}+H D I_{j}}{2}\right)\left|H D I_{i}-H D I_{j}\right|}{\left|H D I_{i}-H D I_{j}\right|+k_{2}}
$$

In Eq.(1): $d_{i j}^{\text {Man_gen }}$ is the generalized Manhattan distance; $d_{i j}$ is the normalized river navigation distance between cities $i$ and $j ; p_{i}$ and $p_{j}$ are the normalized student population for cities $i$ and $j$, respectively; $H D I_{i}$ and $H D I_{j}$ are the normalized UN HDI for cities $i$ and $j$, respectively; $k_{1}$ and $k_{2}$ are extremely small constants compared to other terms and, in this case, were determined to equal $10^{-4}$. These two constants are intended to prevent indetermination in expression (1), when $i=j$, for it satisfies condition of reflexivity.

This distance hereby proposed is proximity measure, for they satisfy conditions of similarity, positivity, and reflexivity (Xu and Wunsch, 2008). However, such distance is not proximity metric, for it fails to satisfy the triangle inequality condition. The parameters used in Eq.(1) were normalized using median values, Eq.(2):

$$
x_{i}=x_{i}^{*} / X_{i}
$$

In Eq.(2): $x_{i}^{*}$ stands for non-normalized parameters distance, population or UN's HDI for cities; $x_{i}$ is the normalized parameter value; $X_{i}$ is the median (Bussab and Morettin, 2009) of a parameter $x_{i}^{*}$. The index proposed in this study for evaluating a location solution is given by means of Eq.(3):

$$
\text { Index }=\left(\frac{\sum_{i=1}^{n} \sum_{j=1}^{n} d_{i j} x_{i j}}{n-p}\right)^{-1}+\frac{\sum_{i=1}^{n} p_{i} x_{i i}}{p}+\left(\frac{\sum_{i=1}^{n} U N^{\prime} s H D I_{i} x_{i i}}{p}\right)^{-1}
$$

In Eq.(3): $d_{i j}$ is the fluvial distance obtained in a location solution, normalized by maximum and minimum values, between city $i$ with no college to city $j$ with a college nearest to it; $p_{i}$ is the population of city $i$, normalized by maximum and minimum values, of population of cities with a college; UN's HDI are the UN HDI, normalized by maximum and minimum values, of cities with a college or university; $p$ and $n$ are the total number of colleges and total number of cities, respectively, with $0<$ $p<n$. Eq.(8) defines the variable $x_{i j}$.

\section{Problem Modeling with p-median}

This model aims to find an optimal solution for allocating higher education institution using a multiobjective approach. Mathematical modeling for the p-median problem on locating education schools in this study corresponds to:

Minimize:

$$
f=\sum_{i=1}^{n} \sum_{j=1}^{n} d_{i j}^{\text {Man_gen }} x_{i j}
$$

Subject to: 


$$
\begin{gathered}
\sum_{i=1}^{n} x_{i i}=p \\
\sum_{j=1}^{n} x_{i j}=1, \quad \forall i \in\{1, \ldots, n\} \\
x_{i j}=\left\{\begin{array}{c}
\text { municipality } i \text { is nearest to } j \text { than any other } \\
\text { municipality with an allocated school; } \\
\sum_{i=1}^{n} x_{i j} \leq n x_{j j}, \quad \forall j \in\{1, \ldots, n\}
\end{array}\right.
\end{gathered}
$$

The p-median modeling just presented is a classical one. The only difference is that the objective function of Eq.(4) minimizes the generalized Manhattan distance. The constraint of Eq.(5) determines that precisely $\mathrm{p}$ facilities must be open. Constraint of Eq.(6) requires that each city be assigned a single campus. Constraint of Eq.(7) forces cities with no allocated schools to be associated only with cities with allocated schools. Eq.(8) indicates the binary nature of the decision variables.

\section{Genetic Algorithm modeling for solve p-median problem}

Holland (1975) is credited with originally designing the first genetic algorithm (GA). According to Chong and Zak (2013), the main steps of GA are defined in the flowchart of Figure 1. The genetic algorithm starts with a population $P(0)$ of $\mathrm{N}$ chromosomes. The chromosome is an encoding of the problem information and encompasses the following data: alphabet, length and encoding. For the p-median problem of this paper, we use the following data: alphabet $-\{0,1\}$; length -62 ; encoding -0 corresponds to a city without a college and 1 corresponds to a city with a college. The stopping criterion used is the number of iterations of the GA. Originally, the fitness function is the function given by Eq.(4), using the generalized Manhattan distance. Next, we discuss the three operators of the GA, selection, crossover and mutation used for solving the p-median problem. The last two are used in the evolution stage shown in Figure 1.

The selection operator is employed to select the members of the mating pool, $M(k)$. The size of the mating pool, $\mathrm{N}$, is the same size of the population $P(k)$. To select the members for the mating pool, the roulette-wheel scheme was used. The probability of selecting a member of $P(k)$ for the mating pool using the roulette was defined through the linear rank method. This probability is given in Eq.(9).

$$
p\left(s_{i}\right)=\operatorname{rank} s_{i} / \sum_{k=1}^{n} \operatorname{rank} s_{k}
$$

As the problem is of minimization, the fitness function values were ordered by decreasing values. The value of the fitness function was not used for the probability 
calculation because high values of the fitness function dominate the population, generating a premature convergence of GA.

To pick parents for crossover, two chromosomes were randomly selected from the mating pool. So, the probability of selecting a chromosome from the mating pool is given by $p_{c}=1 / N$. The crossover operation was carried out as proposed by Picek et al. (2013). These authors showed that a combination of several operators result in a better performance for the GA. In this study, the following operators were used: 1) one-point crossover; 2) two-point crossover; 3) uniform crossover; and 4) random operator. For each one of these operators, an occurrence probability of $0.02,0.03,0.05$ and 0.9 was defined. The three first operators can generate a solution with a number of cities with allocated schools different from $\mathrm{p}$. These solutions are called inviable solutions. Figure 2 illustrates the generation of an inviable solution with the uniform operator. For this example, a chromosome was employed with length equal to 10 and $p=4$. With the crossover random mask, the offspring chromosome has five cities with allocated schools. To solve this problem, the second term of a new fitness function, Eq.(10), penalizes chromosomes with a number of cities with allocated schools different from $p$. In some results that will be presented in the next section, some cities must be considered fixed in the solution. In these cases, term 3 of Eq.(10) penalizes the solutions that do not have these cities.

$$
F(X)=f(X)+|S-p| * \max \left(d_{i j}^{\text {Man_gen }}\right)+N * \max \left(d_{i j}^{\text {Man_gen }}\right)
$$

In Eq.(10): $F(X)$ is the fitness function with type 1 and type 2 penalties; $f(X)$ is the original fitness function defined by Eq.(4); $S$ is the number of cities with schools in the location solution; $N$ is the number of fixed cities not present in a location solution.

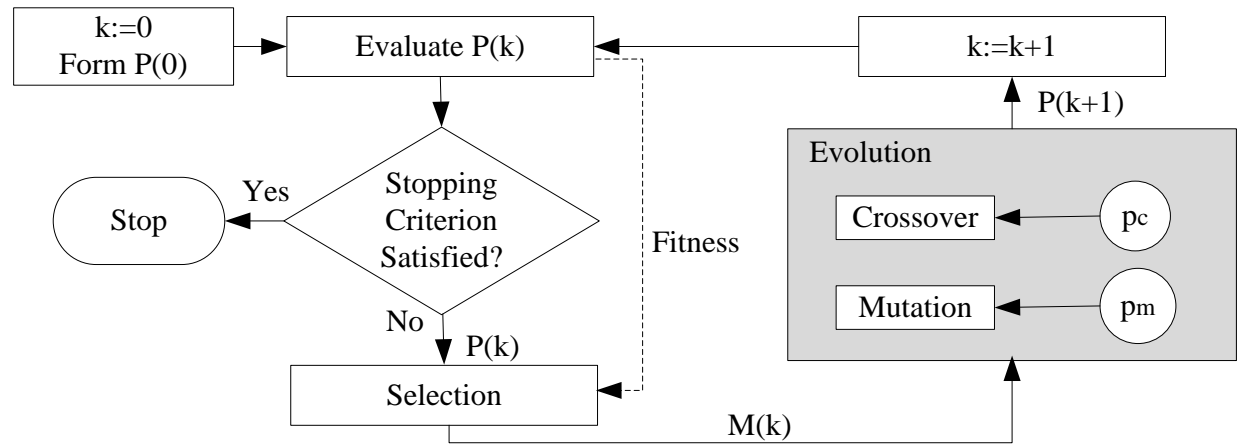

Figure 1. Steps of Genetic Algorithm (After Chong and Zak, 2013). $P(k)-$ population at instant $\mathbf{k} ; \boldsymbol{p}_{c}$ - crossover probability; $\boldsymbol{p}_{m}$ - mutation probability.

\begin{tabular}{|c|c|c|c|c|c|c|c|c|c|c|}
\hline rent 1 & \begin{tabular}{|l|}
0 \\
\end{tabular} & 0 & 1 & 0 & 0 & & & & & 0 \\
\hline arent 2 & 0 & 1 & 0 & 0 & 1 & 0 & 0 & 1 & & 0 \\
\hline ssover mask & 0 & 1 & 1 & 1 & 0 & 1 & 0 & & & 0 \\
\hline ffspring & \begin{tabular}{|l|}
0 \\
\end{tabular} & & 1 & ) & 1 & & & & & \\
\hline
\end{tabular}

Figure 2. Generating inviable solutions with the uniform operator. Only for this example, the chromosome length was equal to 10 and $p=4$.

To implement the random operator, we adopted the following approach: first, the chromosome length was transformed from 62 to $p$. Each one of the $p$ genes represents the decimal position of the 1's in the original chromosome. In the sequence, a 
random mask, of size p, like the one in the uniform crossover, is generated. With this mask, the first offspring is generated. For generating the second offspring, this mask is inverted. Figure 3(a) illustrates this process. As shown, in the offspring there are genes duplicated. To solve this problem, from the set of decimal numbers of both parents that are not in one offspring, one choses a random decimal number to change the duplicated value. Figure 3(b) illustrates this process for offspring 1.

\begin{tabular}{|c|c|c|c|c|c|c|c|c|}
\hline Parent 1 & 50 & 22 & 15 & 38 & 2 & 4 & 62 & 7 \\
\hline Parent 2 & 15 & 10 & 1 & 22 & 4 & 6 & 7 & 38 \\
\hline Crossover mask & 1 & 1 & 1 & 0 & 1 & 0 & 0 & 1 \\
\hline Offspring 1 & 50 & 22 & 15 & 22 & 2 & 6 & 7 & 7 \\
\hline Inverted mask & 0 & 0 & 0 & 1 & 0 & 1 & 1 & 0 \\
\hline Offspring 2 & 15 & 10 & 1 & 38 & 4 & 4 & 62 & 38 \\
\hline
\end{tabular}

(a)

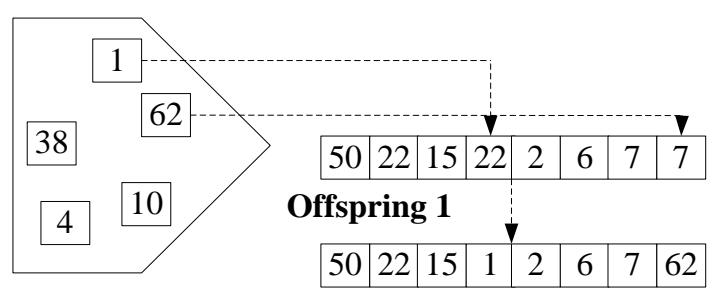

(b)

Figure 3. Random operator used for implementing crossover: (a) generating offspring; (b) eliminating duplicated genes.

For mutation step, the reciprocal exchange mutation called a Twors mutation operator was used (Abdoun et al., 2012). This operator selects two genes randomly and then swaps its values. Evidently, no mutation takes place when the two selected genes have the same value. To prevent this situation, we have adapted the Twors mutation operator as follows. Initially, the genes of a chromosome are divided in two subsets: a) one subset composed of genes with values equal to $1, \mathrm{C}_{1}$; b) another subset composed of position genes with values equal to $0, \mathrm{C}_{2}$. Subsequently, one gene is selected randomly from each subset, $C_{1}$ and $C_{2}$, with uniform probability $p_{1}=1 / C_{1}$ and $p_{2}=1 / C_{2}$, respectively. Then, these two genes are swapped between $\mathrm{C}_{1}$ and $\mathrm{C}_{2}$. The probability $p_{m}$ of a given chromosome suffers a mutation is 0.2 .

The parameters used in this study for GA are described in the sequence. Population size $=300$. Maximum number of iterations $=200 * \mathrm{p}$. Number of individuals selected for crossover $=80 \%$ of population size. Number of individuals selected for mutation $=20 \%$ of population size. The simulation for this heuristic was performed at MATLAB R2014a on a ASUS Intel(R) Xeon(R) Processor @1.80-2.40 GHz computer with 8 GB of RAM and Windows 10.

\section{Results obtained with the GA}

The results section comprises three subsections. The first one shows results obtained with our GA that meet the REUNI requirements. The second section evaluates the existing campus locations of the federal system, in Amazonas state, comparing them with similar locations, obtained with our GA algorithm. Finally, the third section, presents a proposal for expanding federal system to 10 and 15 campuses, preserving the current system location.

\subsection{Location solutions that meet REUNI criteria}

In this study, location solutions with number of colleges varying from 10 to 50 were obtained for GA algorithm. Table 1 shows a reduced set of these results (only 13 values), for GA. 
Table 1. Results of locations with number of universities or colleges varying from 10 to 50, for GA algorithm.

\begin{tabular}{|c|c|c|c|c|c|c|c|}
\hline $\begin{array}{c}\text { Number } \\
\text { of } \\
\text { colleges }\end{array}$ & $\begin{array}{c}\text { Mean } \\
\text { fluvial } \\
\text { distance }\end{array}$ & $\begin{array}{c}\text { Mean } \\
\text { SSP }\end{array}$ & $\begin{array}{c}\text { Mean } \\
\text { UN HDI }\end{array}$ & $\begin{array}{c}\text { Evaluation } \\
\text { index }\end{array}$ & $\begin{array}{c}\text { Meets } \\
\text { REUNI } \\
\text { requirement? }\end{array}$ & $\begin{array}{c}\text { Maximum } \\
\text { fluvial } \\
\text { distance }\end{array}$ & $\begin{array}{c}\text { Execution } \\
\text { time (s) }\end{array}$ \\
\hline 10 & 272.90 & $21,938.40$ & 0.578 & 21.08 & No & 1001 & 275.92 \\
\hline 14 & 223.27 & $16,657.57$ & 0.579 & 25.24 & No & 616 & 398.93 \\
\hline 18 & 191.23 & $13,424.67$ & 0.574 & 29.23 & No & 505 & 549.29 \\
\hline 22 & 170.03 & $11,285.27$ & 0.566 & 32.79 & No & 505 & 691.95 \\
\hline 26 & 148.50 & $9,785.15$ & 0.559 & 37.41 & No & 402 & 882.24 \\
\hline 30 & 130.72 & $9,064.67$ & 0.556 & 42.32 & No & 324 & $1,186.82$ \\
\hline 34 & 129.96 & $8,082.76$ & 0.552 & 42.66 & No & 285 & $1,214.22$ \\
\hline 38 & 133.92 & $7,488.74$ & 0.553 & 41.41 & No & 285 & $1,505.66$ \\
\hline 42 & 116.65 & $6,856.14$ & 0.555 & 47.22 & No & 285 & $1,749.85$ \\
\hline 46 & 93.19 & $6,778.52$ & 0.559 & 58.70 & No & 226 & $1,966.97$ \\
\hline 48 & 93.93 & $6,531.63$ & 0.559 & 58.23 & Yes & 170 & $2,398.75$ \\
\hline 49 & 92.54 & $6,535.10$ & 0.560 & 59.09 & Yes & 170 & $2,074.14$ \\
\hline 50 & 93.08 & $6,458.48$ & 0.560 & 58.74 & Yes & 170 & $2,387.90$ \\
\hline
\end{tabular}

The simulations use the generalized distance shown in Eq.(1). For these solutions, we calculated: the average fluvial distances between cities without a university or college to the nearest city with a university or college; the average SSP population and UN HDI of cities with an allocated high school; and the evaluation index. As shown in Table 1, for GA algorithm, the locations with 48, 49 and 50 campuses meet the REUNI requirement: the maximum distance of a city without a university or college to a city with a university or college is less than $200 \mathrm{~km}$. The conclusion is that to meet the REUNI requirements, a high number of universities or colleges must be constructed. This is impractical, not only due to the high cost of the solution, but also because it implies founding a university or college in small cities, with an insufficient SSP population.

\subsection{Evaluation the existing campus locations of the federal system in Amazonas state}

This section compares the locations obtained with our GA algorithm with the current distribution of Federal University campuses. Section 2 shows that UFAM has 6 campuses in Amazonas State. Figure 4 shows a comparison of GA location with the current location of UFAM. In this figure, the urban and rural areas of the cities are shown. The blue color indicates that a city was chosen by both GA and UFAM. The gray color highlights cities selected only by UFAM. The green color indicates cities selected only by GA. Table 2 shows the mean fluvial distance, mean SSP, mean UN HDI and evaluation index computed for these two locations. 


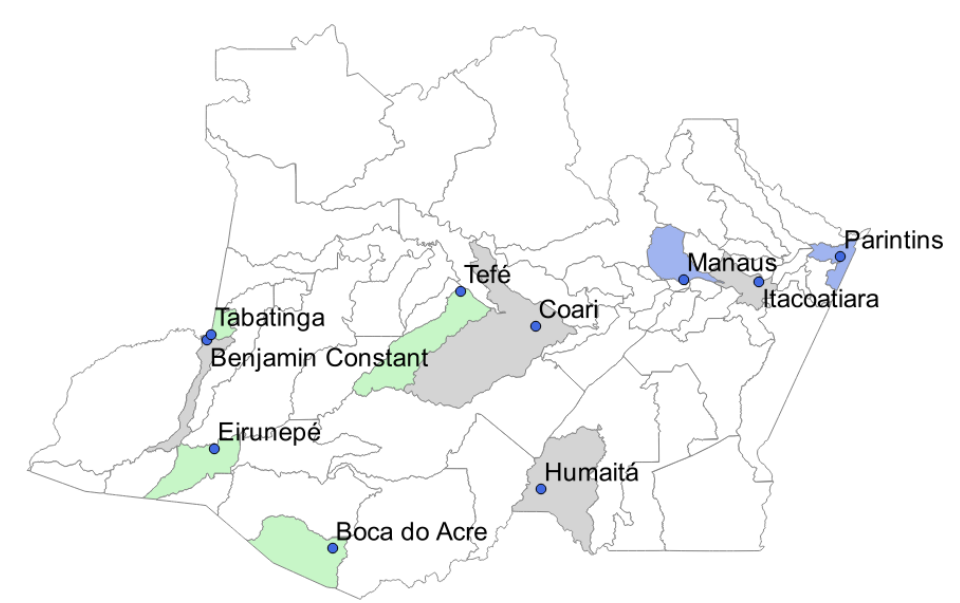

Figure 4. Location solutions perfomed by GA compared to current distribution of UFAM.

As shown in Figure 4, the GA algorithm selected the following cities: Manaus, Parintins, Tefé, Tabatinga, Eirunepé and Boca do Acre. The p-median modeling optimized by GA method prioritizes cities with a high number of inhabitants, such as Manaus, Parintins, Tefé and Tabatinga. Those cities have a population greater than 60,000 dwellers and cities with lower values of UN HDI, such as Eirunepé and Boca do Acre, 0.563 and 0.588 , respectively. Differing from our approach, the location produced by UFAM prioritizes, in general, cities with a higher population.

Table 2 shows mean fluvial distance, mean SSP, mean UN HDI and evaluation index computed for these two locations.

According to Table 2, GA algorithm results in better value of the evaluation index than the UFAM location. The best value for the evaluation index corresponds to GA algorithm, 17.28. This behavior of the evaluation index is due to the lower value of mean fluvial distance obtained with our GA algorithm.

Table 2. Mean values of fluvial distance, SSP, UN HDI and evaluation index for locations of 6 campuses of UFAM and GA algorithm.

\begin{tabular}{|c|c|c|c|c|}
\hline Dis tribution & $\begin{array}{c}\text { Mean fluvial } \\
\text { distance }\end{array}$ & Mean SSP & Mean UN HDI & $\begin{array}{c}\text { Evaluation } \\
\text { index }\end{array}$ \\
\hline UFAM & 536.64 & $38,131.00$ & 0.634 & 11.23 \\
\hline GA & 328.50 & $36,538.33$ & 0.634 & 17.28 \\
\hline
\end{tabular}

\subsection{Expansion proposal for Federal campus}

It is very expensive to reallocate existing schools already established in cities of the interior of Amazonas State. So, in this section, we propose an expansion of the current campuses of UFAM, preserving the current existing schools. For this system, we propose an expansion to 10 and 15 schools. Figures 5(a) and 5(b) show the predicted expansion of UFAM for 10 and 15 campuses, respectively. In these figures, the current existing schools are highlighted in color, and the new allocation schools are marked green.

As shown in Figure 5(a), the p-median problem solved by the GA algorithm selected the following cities for developing 4 new schools: Pauini, Eirunepé, Guajará and Tefé. Our proposal of opening 4 new campuses for UFAM using the p-median modeling, presented in this study, prioritizes cities with a high number of inhabitants, 
such as Tefé that has a population greater than 60,000 inhabitants and cities with lower values of UN HDI, such as Pauini, Eirunepé and Guajará, 0.496, 0.563 and 0.532, respectively.

As shown in Figure 5(b) the p-median problem solved with the GA algorithm method selected the following cities for creating 9 new schools: Apuí, Boca do Acre, Canutama, Eirunepé, Guajará, Ipixuna, Itamarati, Pauini and Tefé. This expansion prioritizes cities with a high number of inhabitants, such as Tefé that has a population greater than 60,000 inhabitants and cities with lower UN HDI values, such as Boca do Acre, Canutama, Eirunepé, Guajará, Ipixuna, Itamarati, Pauini, 0.588, 0.530, 0.563, $0.532,0.481,0.477$ and 0.496 , respectively. The city of the Apuí has a relatively high UN HDI value of 0.637 , and a lower population, around 20,648 inhabitants. The question is why was this city selected instead of the city of São Gabriel da Cachoeira? The answer is that the first city is farther away from large urban centers such as Manaus than the second one, $1,365 \mathrm{~km}$ versus $1,001 \mathrm{~km}$ of fluvial distance, respectively.

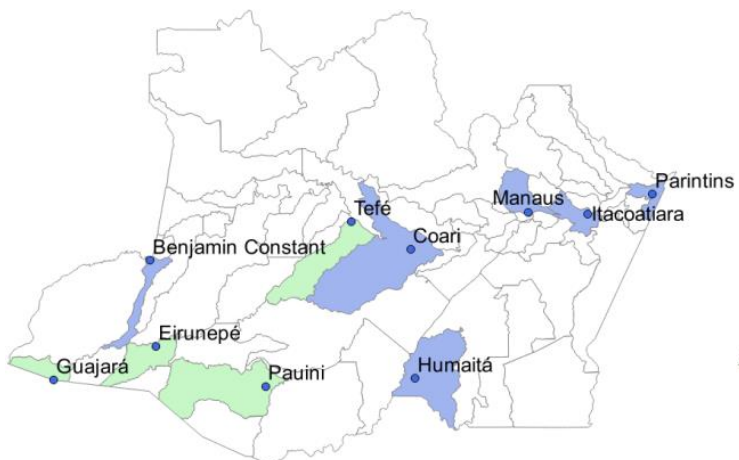

(a)

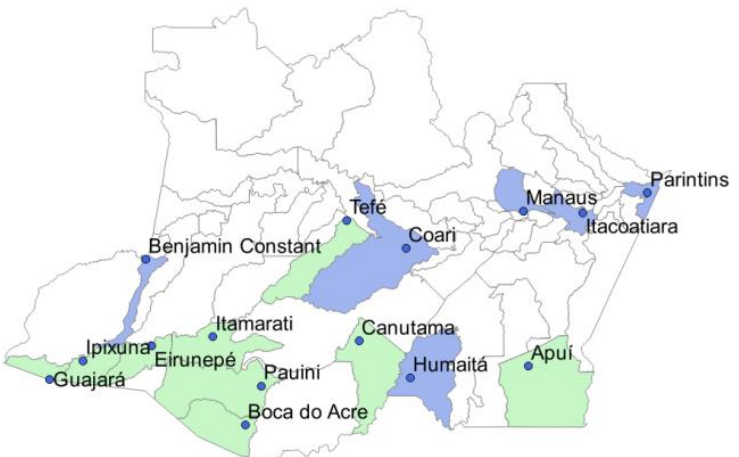

(b)

Figure 5. Proposal for expanding the Federal University of Amazonas: (a) 10 campuses; (b) 15 campuses. Blue color: cities currently with institutions of higher learning. Green color: cities chosen for establishing new schools.

One can observe that the proposal for expanding UFAM, based on a multiparametric approach, selects cities mainly in the Southwest subregion of Amazonas state. In this region there are many cities with lower UN HDI values, with considerable fluvial distances between them and great population centers, such as Manaus, Parintins, etc. Thus, another contribution of this work is to emphasize the necessity of social development of these cities.

\section{Conclusion}

This study proposed a new methodology for a multiparameter approach using the pmedian. This was possible by introducing generalized Manhattan distance, a proximity measure, that, besides the geographic distance, allows for including other parameters relevant to the nature of the problem. In this study, the other parameters considered were the population of secondary pupils and the United Nations' Human Development Index. These parameters are normalized using median approach. The study proposes an optimization expression that allows direct and inverse dependence with the parameter.

This new multiparametric approach for the p-median problem was applied to a case study of university in Amazonas State, situated in the northern region of Brazil, with 62 cities. In this study, genetic algorithm heuristic was employed to solve the p- 
median location problem in 62 cities. To comply with REUNI requirements in Amazonas State, using the multiparametric approach, a minimum of 48 cities with colleges is required. This is an impractical number of schools, mainly due to the cost and because it does not justify establishing a university in a very small city.

In Amazonas State, the Federal University of Amazonas, an institution of higher learning, operating in 6 cities. To compare with these currently established schools, simulations using GA algorithm with the same number of schools were done. The locations obtained with the our GA algorithm result in lower mean distances between cities with schools and cities with no schools compared with the existing distribution of schools.

Finally, the main contribution of this study is to propose a guide for expanding the current Federal University, based on a multiparametric approach. In a future study, with the objective of finding a set of solutions in a search space, the Pareto-optimal method will be applied to solve the same problem.

\section{References}

Abdoun, O., Abouchabaka, J., \& Tajani, C. (2012). Analyzing the Performance of Mutation Operators to Solve the Travelling Salesman Problem. International Journal of Emerging Sciences, 2(1), 61-77.

Amaya, J., Peeters, D., Uribe, P., \& Valenzuela, J. P. (2015). Optimization Modeling for Resource Allocation in the Chilean Public Education System. International Regional Science, 39(2), 155-176.

Brazilian Institute of Geography and Statistics - IBGE (2012). Union Official Journal, 1, 65 - 246. Secondary School Students Achievements.

Brazilian Institute of Geography and Statistics - IBGE (2010). XII Demographic Census.

Bussab, W. O., \& Morettin, P. A. (2009). Basic Statistics. (6th ed.). Saraiva Publisher. (Section 3.1: Position Measures).

Chong, E. K. P \& Zak, S. H. (2013). An Introduction to Optimization. (4th Ed.). Canada. John Wiley \& Sons. (Chapter 14: Global Search Algorithms).

Federal University of Amazonas -UFAM (2006). Institutional Development Plan 20062015. http://www.proplan.ufam.edu.br/PDI_06a15.pdf. Accessed: 08.08.16.

Gac, I., Martínez, F., \& Weintraub, A. (2009). A deterministic linear optimization model for allocating schools to zones. Journal of the Operational Research Society, 60, 895-905.

Holland, J. H. (1975). Adaptation in Natural and Artificial Systems. University of Michigan Press.

Kariv, O., \& Hakimi, S. L. (1979). An algorithmic approach to network location problems. II: the p-medians. Journal of Applied Mathematics, 37, 539-560.

Menezes, R. F., \& Pizzolato, N. D. (2014). Locating public schools in fast expanding areas: application of the capacitated p-median and maximal covering location models. Pesquisa Operacional, 34(2), 301-317. 
Ministry of Education (2010). VIII National REUNI Workshop: Federal Universities Consolidation and Expansion 2011-2020, Support for the National Education Plan. Brazil.

National Waterway Transportation Agency - ANTAQ (2013). Characterization of supply and demand in the inland waterways of the Amazon region passengers.

OECD report (2015). Education at a Glance 2015: OECD Indicators. OECD Publishing, Paris. http://dx.doi.org/10.1787/eag-2015-en. Accessed in 29.08.16.

Picek, S., Jakobovic, D., \& Golub, M. (2013). On the recombination operator in the real-coded genetic algorithms, IEEE Congress on Evolutionary Computation, pp. 3103-3110

Pizzolato, N. D., Barcelos, F. B., \& Lorena, L. A. (2004). School location methodology in urban areas of developing countries. International Transactions in Operational Research, 11(6), 667-681.

Teixeira, J., Antunes, A., \& Peeters, D. (2007). An Optimization-Based Study on the Redeployment of a Secondary School Network. Environment and Planning B: Planning and Design, 34(2), 296-315.

Xavier, C. M., Costa, M. G. F., \& Costa Filho, C. F. F. (2016). Optimizing Universities Allocation with Integer Programming Using a New Distance Measure. In: 5th International Conference on Engineeering Optimization (EngOpt), Iguassu FallsBrazil. Proceedings of 5th EngOpt, 2016. v. 1. p. 1-10.

Xu, R., \& Wunsch, D. C. (2008). Clustering. IEEE Press Series on Computational Intelligence (Section 2.2: Definition of Proximity Measures). 